\title{
Produção de matéria seca e trocas gasosas em cultivares de mamoneira sob níveis de irrigação ${ }^{1}$
}

\author{
Cley A. S. de Freitas ${ }^{2}$, Alexandre R. A. da Silva ${ }^{2}$, Francisco M. L. Bezerra ${ }^{2}$, \\ Claudivan F. de Lacerda', João V. Pereira Filho' \& G eocleber G. de Sousa ${ }^{2}$
}

\section{RESU M 0}

Este trabalho teve o o bjetivo de avaliar os efeitos de cinco níveis de irrigação por gotejamento, em três cultivares de mamoneira (IAC Guarani, Mirante 10 e BRS Paraguaçu) mediante a quantificação da produção de matéria seca pelas diferentes partes da planta (limbo foliar, caule e pecíolo) e a mensuração das trocas gasosas (fotossíntese, condutância estomática e transpiração). O experimento foi conduzido no campo, na Fazenda Experimental Vale do Curu, Pentecoste, CE, sob delineamento experimental em blocos casualizados com parcelas subdivididas, em esquema fatorial $5 \times 3$ e com três repetições. Os tratamentos foram cinco lâminas de irrigação $(25,50,75,100$ e $125 \%$ da evaporação do tanque Classe "A") e três cultivares. O s diferentes níveis de irrigação influenciaram as variáveis: massa seca do pecíolo, condutância estomática e fotossíntese; os valores máximos para essas variáveis foram obtidos com o nível de irrigação correspondente a $125 \%$ da evaporação no tanque Classe A. Houve uma resposta diferenciada na produção de biomassa e nas trocas gasosas entre as três cultivares avaliadas em todas as variáveis estudadas, exceto na massa seca do pecíolo.

Palavras-chave: Ricinus communis, biomassa, fotossíntese

\section{Dry mass production and gas exchanges in castor bean cultivars under different irrigation levels}

\begin{abstract}
This study was aimed at evaluating the effects of five levels of drip irrigation in three castor bean cultivars (IAC Guarani, M irante 10 and BRS Paraguaçu) by measuring the dry mass production by the different plant parts (leaf blade, petiole and plant stem) as well as by measuring the gas exchange processes (photosynthesis, stomatal conductance and transpiration). The experiment was conducted in the field, at the Fazenda Experimental, Vale do Curu, Pentecoste, Ceará (Br). The experiment was conducted in a randomized blocks in a $5 \times 3$ factorial scheme, in split plots with three repetitions. The treatments were five irrigation levels $(25,50,75,100$ and $125 \%$ of the class " $A$ " pan evaporation (CAE) applied to the three cultivars. The different irrigation levels influenced the variables: petiole dry mass, stomatal conductance and photosynthesis, and maximum values for these variables were obtained with irrigation level corresponding to $125 \%$ of the Class A pan evaporation. There was a different response in biomass production and gas exchanges from each of the three cultivars, in all variables, except in petiole dry mass.
\end{abstract}

Key words: Ricinus communis, biomass, photosynthesis

\footnotetext{
${ }^{1}$ Pesquisa financiada pelo Banco do Nordeste

2 DENA/U FC, Av. Mister Hull s/n, Campus do Pici, BI. 804, CEP 60455-760, Fortaleza, CE. Fone: (85) 3366-9758. E-mail: anderson_agrotec@yahoo.com.br; alexandre_reuber@hotmail.com; mbezerra@ufc.br; cfeitosa@ufc.br joao_valdenor@hotmail.com; sousamsa@yahoo.com.br
} 


\section{INTRODUÇÃO}

O Nordeste brasileiro concentra a maior produção nacional de mamona. A cultura tem sido apontada como a principal matéria-prima para uso no Programa Nacional de Biodiesel, devido à excelente adaptação às condições edafoclimáticas predominantes na região. De acordo com o Projeto de Lei 3.368 e com a medida provisória 214, a partir de 2008 deverão ser adicionados $2 \%$ de biodiesel ao diesel de petróleo e $5 \%$ a partir de 2013 (Holanda, 2006).

De todos os recursos de que as plantas precisam para o crescimento, a água é o mais limitante à produtividade agrícola visto ser essencial aos diversos processos metabólicos das plantas, sobretudo durante o período inicial de desenvolvimento (Souza et al., 2001).

Para Souza et al. (2007), a deficiência hídrica pode afetar o surgimento de novos cachos e causar queda na produção, já que a mamoneira é uma planta de crescimento indeterminado, crescendo e produzindo enquanto houver disponibilidade de água e nutrientes. Segundo Schurr et al. (2000), o estresse hídrico na mamoneira afeta seu desenvolvimento e a taxa de assimilação de $\mathrm{CO}_{2}$ e, desta forma, as plantas apresentam estrutura foliar reduzida. Por outro lado, o aumento da disponibilidade hídrica é responsável por uma atividade de crescimento mais pronunciada e eficiente. Conforme Koutroubas et al. (2000), a escassez hídrica afeta negativamente o florescimento e o teor de óleo na mamoneira.

No que diz respeito às trocas gasosas, as plantas com metabolismo fotossintético $\mathrm{C}_{3}$ e taxa fotossintética entre 18 e $27 \mathrm{mg} \mathrm{CO}_{2} \mathrm{dm}^{-2} \mathrm{~h}^{-1}$ necessitam de pelo menos 2.900 graus-dia de calor para chegar à maturidade. $\mathrm{O}$ processo de abertura $\mathrm{e}$ fechamento dos estômatos está relacionado principalmente com a intensidade de luz e com o estado de hidratação da folha. Desta forma, o funcionamento dos estômatos e a área foliar influenciam a produtividade do vegetal. Os estômatos controlam a absorção de $\mathrm{CO}_{2}$ e a área foliar determina a interceptação de luz (Beltrão et al., 2001).

A intensidade luminosa, a temperatura, a concentração de $\mathrm{CO}_{2}$, os teores de nutrientes da folha e a umidade do solo, são fatores que afetam a atividade fotossintética dos vegetais. A redução na taxa fotossintética em virtude da deficiência hídrica está relacionada, sobremaneira, ao fechamento dos estômatos. Se a planta perde água a uma taxa superior à sua capacidade de absorção e transporte, o potencial hídrico da folha diminui, levando ao fechamento dos estômatos e à redução da fotossíntese (Marenco \& Lopes, 2005).

Em situação de baixa disponibilidade de água no solo as plantas reduzem a perda de água ao diminuir a condutância estomática. O estresse hídrico causa, em curto prazo, reduções na condutância estomática e no crescimento de folhas a longo prazo; no entanto, ocorre redução na produção de matéria seca das plantas comprometendo significativamente o crescimento e a produtividade (Gollan et al., 1986).

A restrição de água na cultura do milho diminui a condutância estomática e, em contrapartida, a taxa fotossintética. A condutância foliar é o indicador fisiológico que melhor se correlaciona com a fotossíntese em diferentes condições de disponibilidade hídrica (Pereira et al., 2003). Por isso, Sassaki \& Machado (1999), observaram que em trigo duro e trigo normal a queda da taxa de assimilação de $\mathrm{CO}_{2}$ está relacionada principalmente à queda na condutância estomática.

Souza et al. (2001), trabalharam com a videira e observaram diminuição de $50 \%$ na taxa de fotossíntese a partir do sétimo dia após a interrupção da rega e redução da condutância estomática e do potencial hídrico da folha após o nono dia de interrupção da rega. Desta forma, os autores concluíram que a primeira resposta das plantas à deficiência hídrica é o fechamento dos estômatos, que diminui a difusão de $\mathrm{CO}_{2}$ para o mesófilo foliar e causa queda na fotossíntese.

Segundo Larcher (2004), à medida em que a disponibilidade de água no solo diminui a taxa de transpiração decresce, como resultado do fechamento dos estômatos. Este é um dos importantes mecanismos de defesa que as plantas apresentam contra as perdas exageradas de água e o risco de morte por dessecação.

Oliveira et al. (2002), trabalharam com a deficiência hídrica da pupunheira e observaram diminuição da taxa de assimilação de $\mathrm{CO}_{2}$, atingindo valores muito baixos (ao redor de -1,9 MPa) no décimo dia após a interrupção da irrigação indicando que tanto as reduções da fotossíntese como as do potencial de água nas folhas estão relacionadas à deficiência hídrica do solo.

Face ao exposto buscou-se, neste trabalho, avaliar os efeitos de cinco níveis de irrigação por gotejamento em três cultivares de mamoneira (IAC Guarani, Mirante 10 e BRS Paraguaçu) mediante a quantificação da produção de matéria seca pelas diferentes partes da planta (limbo foliar, caule e pecíolo) e a mensuração das trocas gasosas (fotossíntese, condutância estomática e transpiração) nas condições edafoclimáticas do município de Pentecoste, Ceará.

\section{Material E MÉtodos}

O trabalho foi desenvolvido de setembro de 2007 a maio de 2008, na Fazenda Experimental do Vale do Curu (FEVC), pertencente à Universidade Federal do Ceará, em Pentecoste, CE. A cidade fica entre os paralelos $3^{\circ} 45^{\prime}$ e $3^{\circ} 50^{\prime}$ de latitude Sul e os meridianos $39^{\circ} 15^{\prime}$ e $39^{\circ} 30^{\prime}$ de longitude Oeste, com altitude média de 47 m e clima classificado como BSw'h' pelo sistema internacional de Köppen, ou seja, semiárido com chuvas irregulares. O solo é classificado como Neossolo Flúvico e apresenta textura franco-arenosa na camada de 0 a $0,70 \mathrm{~m}$ (EMBRAPA, 1999). A precipitação média anual é de $801 \mathrm{~mm}$, a evaporação média é de $1.475 \mathrm{~mm}$, a temperatura média anual se situa em torno de $27,1^{\circ} \mathrm{C}$ e a média de umidade relativa do ar é 73,7\% (EMBRAPA, 2001). Os dados meteorológicos: temperatura do ar, umidade relativa do ar, evaporação do tanque classe A (ECA) e precipitação, foram obtidos da estação micrometeorológica convencional da Fazenda Experimental Vale do Curu e estão apresentados na Tabela 1.

O preparo da área experimental constou de roçagem, gradagem e marcação das covas no espaçamento de 2 x $1 \mathrm{~m}$. A adubação foi realizada com base na análise química do solo e na necessidade nutricional da cultura. Para suprir prováveis deficiências de micronutrientes, $17 \mathrm{~g}$ de FTE BR 12 foram fornecidos por cova antes da semeadura. Com base na análise química do solo foram aplicados, via fertirrigação, $60 \mathrm{~kg}$ de 
Tabela 1. Condições climáticas* médias medidas durante o experimento

\begin{tabular}{|c|c|c|c|c|c|c|c|}
\hline \multirow{2}{*}{ Ano } & \multirow{2}{*}{ Mês } & T Max. & T Min. & T Méd. & \multirow{2}{*}{ UR (\%) } & ECA & Precipitação \\
\hline & & & $(\stackrel{\circ}{ })$ & & & \multicolumn{2}{|c|}{$(\mathrm{mm})$} \\
\hline \multirow{4}{*}{2007} & Setembro & 36,10 & 21,70 & 28,90 & 49 & 291,1 & - \\
\hline & Outubro & 37,60 & 22,80 & 30,20 & 54 & 328,0 & - \\
\hline & Novembro & 36,50 & 22,00 & 29,25 & 54 & 317,3 & - \\
\hline & Dezembro & 38,20 & 24,00 & 31,10 & 51 & 306,0 & - \\
\hline \multirow{5}{*}{2008} & J aneiro & 34,20 & 20,80 & 27,50 & 69 & 191,6 & 104,6 \\
\hline & Fevereiro & 36,90 & 24,10 & 30,50 & 67 & 164,6 & 24,4 \\
\hline & Março & 32,10 & 22,70 & 27,40 & 84 & 126,4 & 255,5 \\
\hline & Abril & 31,60 & 22,50 & 27,00 & 81 & 93,0 & 215,0 \\
\hline & Maio & 32,10 & 22,20 & 27,15 & 81 & 114,4 & 193,2 \\
\hline
\end{tabular}

$\mathrm{N} \mathrm{ha}^{-1}, 60 \mathrm{~kg}$ de $\mathrm{P}_{2} \mathrm{O}_{5} \mathrm{ha}^{-1}, 20 \mathrm{~kg}$ de $\mathrm{K}_{2} \mathrm{O} \mathrm{ha}^{-1}$, tendo-se usado, como fontes de nutriente, sulfato de amônio, fosfato de monoamônio (MAP) e sulfato de potássio, parcelados em 34 aplicações, durante os primeiros 74 dias após a emergência (DAE), compreendendo o período vegetativo da cultura.

A área total ocupada pelo experimento foi de $2.700 \mathrm{~m}^{2}(90 \mathrm{x}$ $30 \mathrm{~m})$. O delineamento experimental foi em blocos casualizados com parcelas subdivididas, em esquema fatorial $5 \times 3$, com três repetições. Cada bloco era composto por 15 linhas de plantas, em que foram distribuídos 5 níveis de irrigação baseados na evaporação do tanque classe A (ECA), sendo T1 $=0,25 \mathrm{ECA}$, $\mathrm{T} 2=0,50 \mathrm{ECA}, \mathrm{T} 3=0,75 \mathrm{ECA}, \mathrm{T} 4=1,00 \mathrm{ECA}$ e $\mathrm{T} 5=1,25 \mathrm{ECA}$, considerados parcela. Cada parcela foi dividida em três partes e distribuída, ao acaso, contendo 10 plantas de cada cultivar (IAC Guarani, Mirante 10 e BRS Paraguaçu), caracterizando a subparcela.

Utilizou-se um sistema de irrigação por gotejamento com um gotejador por planta, do tipo autocompensante, modelo Katif, com vazão de $3,75 \mathrm{~L} \mathrm{~h}^{-1}$. No período de estabelecimento da cultura (primeiros 25 dias após a germinação), todos os tratamentos receberam a mesma lâmina de irrigação, correspondente a $100 \%$ da ECA, de modo a se obter boa uniformidade do estande. A partir do $25^{\circ}$ dia após a germinação, a irrigação de reposição foi realizada com turno de rega de dois dias e a lâmina de irrigação foi baseada na evaporação do tanque Classe "A" (ECA), de acordo com cada tratamento.

Realizou-se uma coleta de plantas aos $74 \mathrm{DAE}$, cortando-se 5 plantas de cada subparcela rente à superfície do solo e se separando as amostras em limbo foliar, pecíolo e caule. Após a obtenção da massa fresca, amostras homogêneas de cada parte da planta foram acondicionadas em sacos de papel, secadas em estufa a $60^{\circ} \mathrm{C}$ até peso constante e pesadas para a obtenção do teor de matéria seca. A produção de matéria seca foi obtida multiplicando-se a produção de massa fresca pelo teor de matéria seca das diferentes partes da planta. Aos 81 DAE foram feitas medições das trocas gasosas (fotossíntese, transpiração e condutância estomática) em folhas completamente maduras, por meio de um analisador de gás no infravermelho (IRGA, ADC System). As leituras foram realizadas entre $9 \mathrm{e} 11 \mathrm{~h}$ sob as condições climáticas reinantes na área experimental.

Os resultados obtidos foram submetidos à análise da variância pelo teste $\mathrm{F}$ a 1 e 5\% de probabilidade. Quando se constatou efeito significativo compararam-se as médias obtidas entre as cultivares (subparcelas) pelo teste de Tukey, em nível de 5\% de probabilidade e se utilizou a regressão polinomial para analisar o efeito das lâminas de irrigação (parcelas), buscando-se ajustar equações com significados biológicos. Com o auxílio do software "SAEG 9.0 - UFV" foram selecionados os modelos que apresentaram maiores níveis de significância e coeficiente de determinação $\left(\mathrm{R}^{2}\right)$.

\section{RESULTADOS E DISCUSSÃO}

Na Tabela 2 são apresentados os resumos das análises de variância das variáveis massa seca do limbo foliar (MSL), massa seca do pecíolo (MSP), massa seca do caule (MSC),

Tabela 2. Resumo da análise de variância para a massa seca do limbo foliar (M SL), massa seca do pecíolo (M SP), massa seca do caule (MSC), condutância estomática (CES), fotossíntese (FOT) e transpiração (TRA) em três cultivares de mamoneiras cultivadas sob diferentes níveis de irrigação ${ }^{1}$

\begin{tabular}{|c|c|c|c|c|c|c|c|}
\hline \multirow{2}{*}{ Fontes de variação } & \multirow{2}{*}{ GL } & \multicolumn{6}{|c|}{ Teste F } \\
\hline & & MSL & MSP & MSC & CES & FOT & TRA \\
\hline Total & 44 & & & & & & \\
\hline Total de Redução & 16 & 7,36 & 1,35 & 2,81 & & & \\
\hline Bloco & 2 & 9,50 & 0,10 & 11,05 & & & \\
\hline Lâminas de Irrigação (L) & 4 & $2,62^{\mathrm{ns}}$ & $3,15^{*}$ & $1,88^{\text {ns }}$ & $4,06 *$ & $4,21 *$ & $1,50^{\mathrm{ns}}$ \\
\hline Erro (A) & 8 & & & & & & \\
\hline Cultivares (C) & 2 & $24,99 * *$ & $2,56^{\mathrm{ns}}$ & $3,91^{*}$ & $6,61 * *$ & $10,71 * *$ & $5,79 * *$ \\
\hline Interação (L x C) & & $1,09^{\text {ns }}$ & $4,23 * *$ & $5,30 * *$ & $9,14^{* *}$ & $14,12 * *$ & $10,64 * *$ \\
\hline Resíduo & 28 & & & & & & \\
\hline Média geral & & 234,48 & 57,30 & 703,66 & 0,62253 & 20,77 & 6,60 \\
\hline C. V. $(\%)$ & & 36,25 & 161,27 & 101,89 & 40,82 & 13,79 & 27,28 \\
\hline
\end{tabular}

* significativo a nível de $1 \%$ de probabilidade $(p<0,01)$

* significativo a nível de $5 \%$ de probabilidade $(0,01 \leq p<0,05)$

${ }^{\text {ns }}$ não significativo $(p \geq 0,05)$ 
condutância estomática (CES), fotossíntese (FOT) e transpiração (TRA). Houve efeito significativo (teste F, $1 \%$ de probabilidade) das lâminas de irrigação sobre as variáveis MSP, CES e FOT e efeito significativo das cultivares sobre todas as variáveis estudadas, exceto para MSP. A interação entre os dois fatores estudados (lâminas de irrigação e cultivares) foi significativa para todas as variáveis estudadas, exceto para MSL.

Enfatiza-se a ausência de efeitos significativos das diferentes lâminas de irrigação sobre a transpiração (TRA), contrapondo as tendências naturais dos processos fisiológicos referentes às trocas gasosas. Taiz \& Zeiger (2009) afirmam que em condições de deficiência hídrica as plantas utilizam o mecanismo de fechamento dos estômatos e reduzem a condutância estomática no intuito de restringir a perda de água, reduzindo a transpiração, sacrificando a absorção de $\mathrm{CO}_{2}$ e acarretando, em consequência, redução acentuada da taxa fotossintética e da acumulação de fotoassimilados. Tais assertivas reforçam a interdependência entre as variáveis analisadas; no entanto e de maneira arbitrária, pode-se considerar que a não significância das lâminas de irrigação sobre a transpiração é passível de ser atribuída ao pronunciado efeito de fatores de variação não controlados no experimento, o que é reforçado pelos elevados valores de coeficientes de variação constatados nas variáveis analisadas

Para a massa seca do pecíolo constatou-se que o modelo que melhor se ajustou aos dados das cultivares avaliadas foi o polinomial de $2^{\circ}$ grau para a cultivar Paraguaçu e linear para a cultivar Mirante (Figura 1A). Para a cultivar Guarani ficou evidente, ainda, a partir da análise de regressão, que não houve ajuste adequado para a massa seca do pecíolo embora a análise de variância tenha apontado influência dos tratamentos lâminas de irrigação e de sua respectiva interação com as cultivares. Com o modelo polinomial de $2^{\circ}$ grau ajustado para a cultivar Paraguaçu, estimou-se uma massa seca do pecíolo máxima (296,35 g planta $^{-1}$ ) para o nível de irrigação 63,04\% da ECA, ou seja, o peso médio dos frutos aumentaria do tratamento $25 \%$ da ECA até o nível 63,04\% da ECA e a partir deste nível o peso médio dos frutos começaria a diminuir.

Desta forma e face ao comportamento exibido pelas cultivares mediante a variação da disponibilidade hídrica do solo condicionada pela aplicação das diferentes lâminas de irrigação constata-se que, embora a cultura seja considerada resistente à seca, não significa que sua produção de biomassa não seja influenciada pela quantidade de água disponível no solo, conforme reportam Severino et al. (2006). Resultados semelhantes foram obtidos por Nascimento (2007), ao constatar que a produção média de massa seca da parte aérea foi obtida para o tratamento cujas plantas foram mantidas em solo a $100 \%$ de água disponível, averiguando-se também um decréscimo gradual no acúmulo de fitomassa na medida em que o nível de água no solo foi reduzindo. Por outro lado, a análise de variância não detectou diferença significativa entre cultivares para a variável em questão.

Para a cultivar Mirante com a aplicação das lâminas de 25 a $125 \%$ ECA, foi verificada tendência linear positiva da curva de resposta da massa seca do pecíolo e se constata que a aplicação da lâmina de irrigação referente a $25 \%$ da ECA reduziu a
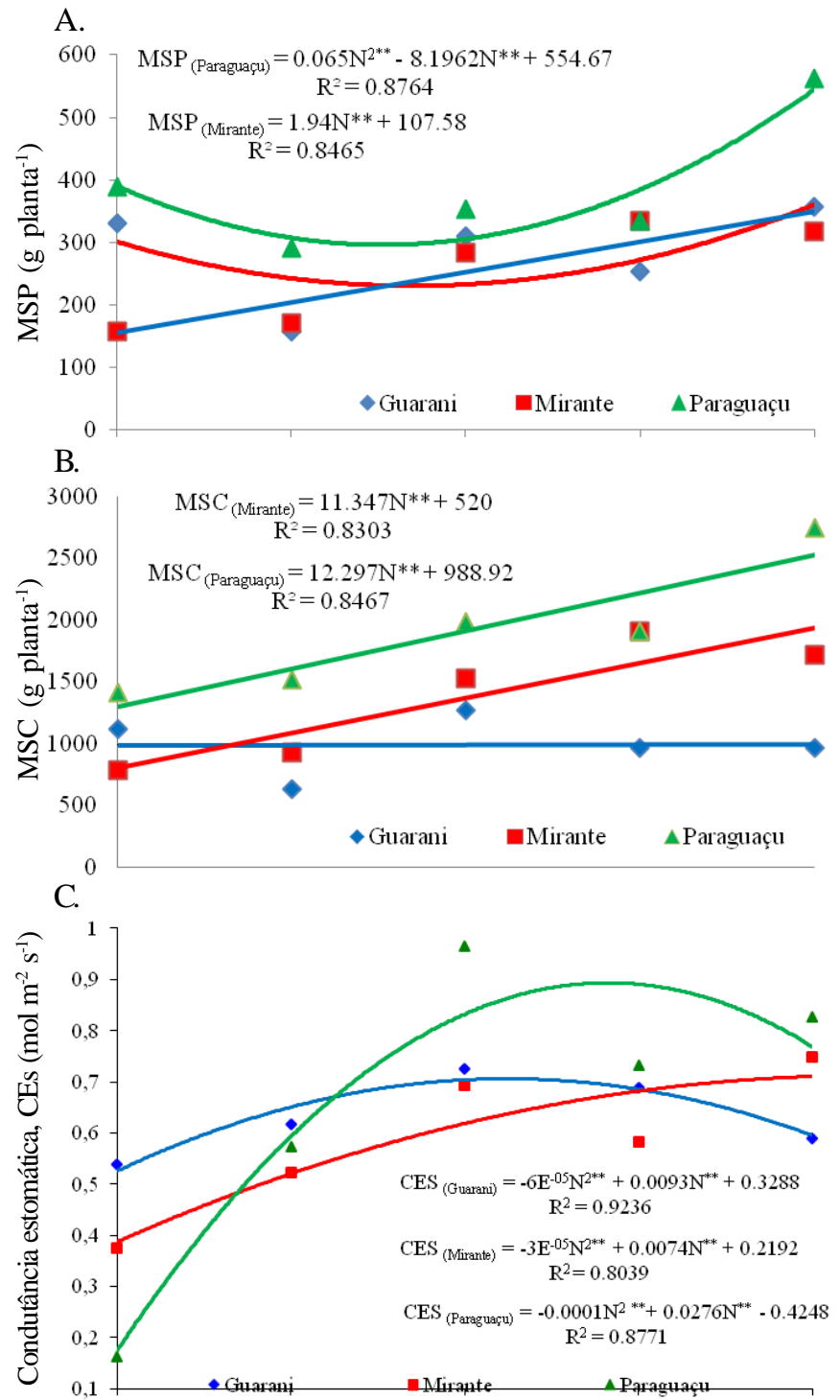

D.

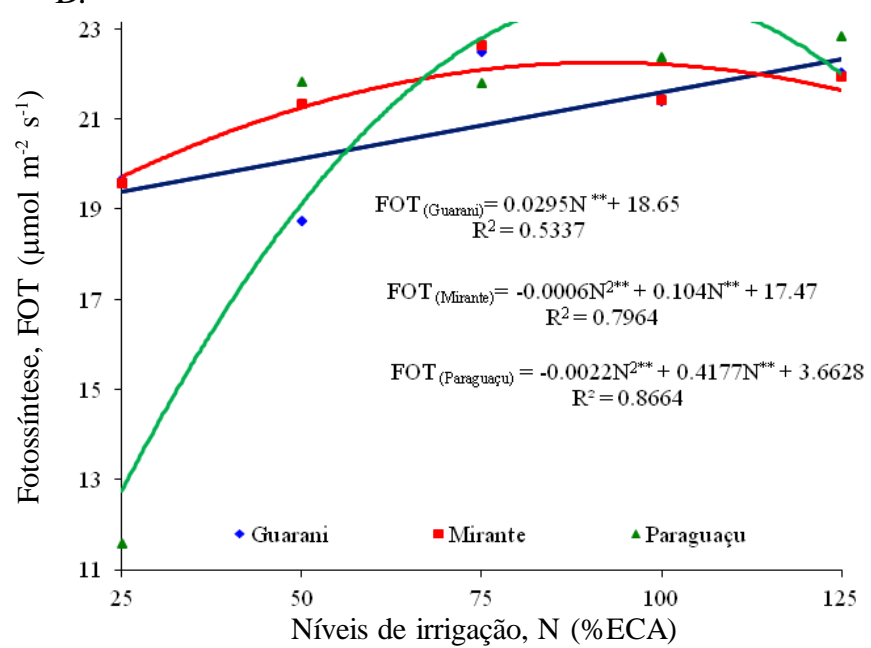

Figura 1. Massa seca do pecíolo - MSP (A), massa seca do caule - MSC (B), condutância estomática (C) e fotossíntese (D) das três cultivares de mamoneira cultivadas sob diferentes níveis de irrigação

produção de matéria seca do pecíolo nas cultivares (Figura 1 B). Tais resultados corroboram com as afirmações citadas por 
Conceição et al. (2004), ao afirmarem que as alterações de fatores ambientais, como a disponibilidade hídrica do solo, por exemplo, podem induzir as plantas a redirecionarem a distribuição dos fotoassimilados e, em consequência, modificar o padrão de crescimento e a morfologia da planta.

Validando os presentes resultados, Martim et al. (2009) discorrem que a escassez hídrica do solo acarreta alterações no crescimento. No presente ensaio é facilmente evidenciado o efeito da escassez de água ao se observar os baixos valores de massa seca do pecíolo (MSP), obtidos nos tratamentos de menor lâmina d'água, evento que se deve às alterações no metabolismo do carbono das células vegetais, que são dependentes do equilíbrio entre fotossíntese e respiração fatos que, possivelmente, também justificam a constatação de efeitos significativos para o fator lâminas de irrigação sobre as variáveis em questão.

A mamoneira distribui seus assimilados prioritariamente nas folhas e pecíolos e, em seguida, os aloca para os racemos, por ocasião dos culminantes acúmulos de matéria seca na planta (Silva, 2008).

A matéria seca do caule seguiu um modelo linear para as cultivares Mirante e Paraguaçu. Para a cultivar Guarani não foi possível ajustar um modelo matemático que representasse o comportamento das cultivares mediante a variação dos níveis de irrigação (Figura 1B). Assim, infere-se que as cultivares Mirante e Paraguaçu responderam de forma semelhante quanto ao incremento na matéria seca do caule em função dos crescentes níveis de irrigação, mesmo diante da influência significativa do efeito das cultivares

Confirmando os resultados obtidos no presente trabalho, Lacerda et al. (2009) avaliaram a sensibilidade da mamoneira a diferentes níveis de água disponível no solo e constataram que a produção de fitomassa foi significativamente influenciada pelo conteúdo de água no solo. Conforme os autores, os tratamentos mantidos a 100 e $90 \%$ da água disponível alcançaram os maiores rendimento, em termos de matéria seca da parte aérea.

Para a condutância estomática pode-se constatar, na Figura 1C, que o modelo que melhor se ajustou aos dados foi o polinomial de $2^{\circ}$ grau para as três cultivares avaliadas. Com as equações provenientes deste modelo aplicado a cada variável foram estimados valores máximos de condutância estomática de 0,68; 0,67 e 1,47 mol m $\mathrm{m}^{-2} \mathrm{~s}^{-1}$, correspondentes aos níveis de irrigação de 77,5; 67,0 e 138,0 \% da ECA, para as cultivares IAC Guarani, Mirante 10 e BRS Paraguaçu, respectivamente. Evidencia-se, assim, que os efeitos das diferentes lâminas de irrigação sobre a condutância estomática foram bem expressivos, o que condiz com Davies \& Zang (1991) quando os autores mencionam que a resposta estomática é frequentemente mais associada ao conteúdo de água no solo do que ao status hídrico da folha. Tais resultados corroboram ainda com informações fornecidas por Heckenberger et al. (1998) ao observarem que as plantas de mamona submetidas a deficiência hídrica sofreram redução nos valores de condutância estomática em decorrência de uma elevação na densidade de estômatos naqueles tratamentos cultivados sob estresse hídrico.

O mecanismo do fechamento dos estômatos no intuito de restringir a perda de água por transpiração pode ser considerado uma estratégia adaptativa utilizada por diferentes espécies visando limitar a perda de água e para exceder a deficiência hídrica, conforme verificaram Naves Barbiero et al. (2000) nas espécies lenhosas Rapanea guianensis e Roupala montana, por Silva et al. (2003) em Tabebuia aureaplantas, Souza et al. (2001) em mudas de videira, e por Liberato et al. (2006) ao analisarem o desempenho fisiológico de plantas jovens de acariquara (Minquartia guianensis Aubl.) também submetidas a deficiência hídrica.

Devido à diminuição da condutância estomática a atividade fotoquímica é restringida de tal forma que, acidentalmente, ocorre a fotoinibição sob condições de acentuado déficit hídrico, tendo como consequência um fechamento quase que completo dos estômatos (Flexas et al., 2006).

A consequência do mecanismo de fechamento dos estômatos é a redução na disponibilidade de $\mathrm{CO}_{2}$, que acarreta alterações entre o balanço apropriado e o transporte de elétrons, o metabolismo de carbono e o consumo de ATPe NADPH que, em conjunto, tornam o fotossistema II ineficiente, comprometendo significativamente a produção de fotossintatos (Tezara et al., 2005).

Estômatos abertos possibilitam a absorção de gás carbono; ao se fecharem, poupam água e restringem o risco de desidratação. À medida em que diminui a disponibilidade de água no solo, a condutância estomática é reduzida, restringido a taxa de transpiração como resposta ao fechamento dos estômatos. Tal comportamento constitui um dos importantes mecanismos de defesa que as plantas apresentam contra as perdas excessivas de água, bem como compõe uma das estratégias adaptativas diante da imposição do déficit hídrico (Inoue \& Martins, 2006).

Desta forma, verificou-se uma conduta contraditória entre os valores encontrados no presente trabalho. Tal fato pode ser justificado pela constatação de diferenças significativas entre as cultivares avaliadas, levando-se em consideração que este comportamento é um reflexo do comportamento diferenciado das cultivares de mamoneira em resposta à irrigação, no que se relaciona com as trocas gasosas.

Para os valores de fotossíntese (FOT), em função dos tratamentos (lâminas de irrigação) evidenciou-se que o modelo matemático que mais se ajustou aos dados foi o polinomial de segundo grau, para as cultivares Mirante 10 e BRS Paraguaçu e linear, para cultivar IAC Guarani (Figura 1D).

A redução da atividade fotossintética como decorrência da deficiência hídrica nos tratamentos submetidos às menores lâminas de irrigação, pode ser mais bem explicada devido ao comprometimento da absorção de $\mathrm{CO}_{2}$ através dos estômatos em resposta às reduções na condutância estomática ou, possivelmente, devido ao dano direto do próprio déficit hídrico sobre o metabolismo fotossintético (Endres et al., 2010). Sausen (2007) analisou os efeitos do déficit hídrico sobre as atividades fotossintéticas da mamoneira, cultivar BRS 149 Nordestina em casa de vegetação nas condições edafoclimáticas do estado do Rio Grande do Sul, Brasil. No trabalho, o autor constatou que a tolerância à deficiência hídrica na mamona está relacionada a um eficiente controle da perda de água pelo fechamento dos estômatos em resposta à redução na disponibilidade de água no solo. 
Tabela 3. M assa seca do limbo foliar (MSL), massa seca do caule (M SC), condutância estomática (CES), fotossíntese (FOT) e transpiração (TRA) das três cultivares cultivadas sob diferentes níveis de irrigação*

\begin{tabular}{|c|c|c|c|c|c|}
\hline \multirow{2}{*}{ Cultivares } & MSL & MSC & \multirow{2}{*}{$\begin{array}{c}\text { CES } \\
\left(\mathrm{mol} \mathrm{m}^{-2} \mathrm{~s}^{-1}\right)\end{array}$} & \multirow{2}{*}{ 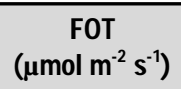 } & \multirow{2}{*}{ 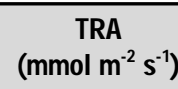 } \\
\hline & \multicolumn{2}{|c|}{ (g planta ${ }^{-1}$ ) } & & & \\
\hline IAC Guarani & $133,54 \mathrm{~b}$ & 314,18 b & $0,69 a$ & $21,23 a$ & $6,90 a$ \\
\hline Mirante 10 & $218,66 b$ & $755,58 a b$ & $0,55 b$ & $19,46 \mathrm{~b}$ & $6,20 \mathrm{~b}$ \\
\hline BRS Paraguaçu & 351,54 a & $1041,22 a$ & $0,61 \mathrm{ab}$ & $21,63 a$ & $6,70 a b$ \\
\hline D.M.S. & 76,84 & 648,19 & 0,08 & 1,21 & 0,51 \\
\hline
\end{tabular}

* Médias seguidas da mesma letra nas colunas não diferem entre si pelo teste de Tukey $(p<0.05)$

Constantemente, o estresse hídrico atenua a taxa fotossintética e a intensidade deste efeito influencia a capacidade de espécies diferentes de lidar com a seca, que também depende da duração do estresse e adaptação genética das plantas (Martim et al., 2009). Neste contexto pode-se inferir que a manutenção da capacidade fotossintética em condições de déficit hídrico do solo é uma importante característica para a manutenção do crescimento e da produtividade na mamoneira, conforme também reporta Sausen (2007).

$\mathrm{Na}$ Tabela 3 são apresentados os valores médios das variáveis massa seca do limbo foliar (MSL), massa seca do caule (MSC), condutância estomática (CES), fotossíntese (FOT) e transpiração (TRA) das cultivares de Mamona para o fator cultivares. Na comparação dos resultados das respostas das variáveis analisadas observaram-se semelhanças e diferenças entre as cultivares.

Na comparação das médias da massa seca do limbo foliar (MSL) entre as cultivares, a BRS Paraguaçu obteve a maior média, diferenciando-se estatisticamente $(\mathrm{p}<0,05)$ das demais cultivares com 351,54 g planta $^{-1}$ seguida da Mirante $10(218,66$ $\left.\mathrm{g} \mathrm{planta}^{-1}\right)$ que não se diferenciou estatisticamente $(\mathrm{p}<0,05)$ da IAC Guarani (Tabela 3).

Analisando-se o efeito das cultivares para a variável massa seca do caule (MSC), contata-se que a cultivar BRS Paraguaçu também exibiu maiores valores $\left(1041,22 \mathrm{~g} \mathrm{planta}^{-1}\right)$, assemelhando-se estatisticamente $(\mathrm{p}<0,05)$ à Mirante 10 $\left(755,58 \mathrm{~g}\right.$ planta $\left.^{-1}\right)$ e diferindo estatisticamente $(\mathrm{p}<0,05) \mathrm{da}$ IAC Guarani $\left(314,18 \mathrm{~g}\right.$ planta $\left.^{-1}\right)$, a qual também não diferiu estatisticamente $(\mathrm{p}<0,05)$ da Mirante 10 (Tabela 3).

Quanto à condutância estomática (CES), também foram observadas diferenças significativas entre as cultivares, de tal forma que a Mirante 10 apresentou menores valores (0,55 mol $\left.\mathrm{m}^{-2} \mathrm{~s}^{-1}\right)$ e se diferenciou estatisticamente $(\mathrm{p}<0,05)$ da IAC Guarani $\left(0,69 \mathrm{~mol} \mathrm{~m}^{-2} \mathrm{~s}^{-1}\right)$ e da BRS Paraguaçu $\left(0,61 \mathrm{~mol} \mathrm{~m}^{-2} \mathrm{~s}^{-1}\right)$; no entanto, ambas não diferiram estatisticamente $(\mathrm{p}<0,05)$ entre si (Tabela 3).

A fotossíntese (FOT) quantificada na cultivar Mirante 10 $\left(19,46 \mu \mathrm{mol} \mathrm{m} \mathrm{m}^{-2} \mathrm{~s}^{-1}\right)$ se diferenciou estatisticamente $(\mathrm{p}<0,05)$ das demais cultivares; apesar disto, não se observou diferença estatística entre a fotossíntese mensurada para as cultivares IAC Guarani $\left(21,23 \mu \mathrm{mol} \mathrm{m}^{-2} \mathrm{~s}^{-1}\right)$ e BRS Paraguaçu $(21.63 \mu \mathrm{mol}$ $\mathrm{m}^{-2} \mathrm{~s}^{-1}$ ) (Tabela 3).

No que diz respeito à variável transpiração (TRA), nota-se que os menores resultados foram obtidos para a Mirante 10 $\left(6,20 \mathrm{mmol} \mathrm{m}^{-2} \mathrm{~s}^{-1}\right)$, que diferiu estatisticamente $(\mathrm{p}<0,05) \mathrm{da}$ IAC Guarani $\left(6,90 \mathrm{mmol} \mathrm{m}^{-2} \mathrm{~s}^{-1}\right)$, que exibiu valores ligeiramente superiores nesta característica quando comparada às demais cultivares; a cultivar BRS Paraguaçu, porém, não diferiu estatisticamente das demais cultivares avaliadas.

Tais resultados apoiam as inferências de Heckler (2002), ao afirmar que as diferentes cultivares de uma cultura pode apresentar comportamento diferenciado de crescimento, alocação de biomassa, produtividade e de outras características de interesse agronômico. Santos et al. (2002) expõem que há uma resposta diferenciada na performance agronômica entre diferentes cultivares de uma espécie vegetal, mesmo quando cultivadas sob as mesmas condições ambientais. Desta forma, a possibilidade de identificação de diferenças entre as cultivares nesta cultura admite o estabelecimento de analogias entre as plantas e a disponibilidade hídrica do solo, contribuindo para a eleição de cultivares adaptadas às condições irrigadas.

\section{CONCLusões}

1. Os diferentes níveis de irrigação influenciaram as variáveis massa seca do pecíolo, condutância estomática e fotossíntese.

2. Os valores máximos das variáveis massa seca do pecíolo condutância estomática e fotossíntese, foram obtidos com o nível de irrigação correspondente a $125 \%$ da evaporação no tanque Classe A.

3. Houve uma resposta diferenciada na produção de biomassa e nas trocas gasosas entre as três cultivares avaliadas, em todas as variáveis estudadas, exceto na massa seca do pecíolo.

4. A cultivar BRS Paraguaçu exibiu maiores valores de massa seca do limbo foliar, massa seca do caule e fotossíntese; já os maiores valores de condutância estomática e transpiração foram observados para a IAC Guarani enquanto a Mirante 10 exibiu os menores valores para todas as variáveis estudadas, exceto na condutância estomática.

\section{LITERATURA CITADA}

Beltrão, N. E. de M.; Silva, L. C.; Vasconcelos, O. L.; Azevedo, D. M. P.; Vieira, D. J. Fitologia. In: Azevedo, D. M. P. de; Lima, E. F. (ed.) O agronegócio da mamona no Brasil. Brasília: Embrapa Informação Tecnológica, 2001. Cap.2, p.37-62.

Conceição, M. K.; Lopes, N. F.; Fortes, G. R. de L. Partição de matéria seca entre órgãos de batata-doce (Ipomoea batatas (L.) Lam), cultivares abóbora e da costa. Revista Brasileira de Agrociência, v.10, p.313-316, 2004.

Davies, W. J.; Zhang, J. Root signals and the regulation of growth and development of plants in drying soil. Annual Review of Plant Physiology and Plant Molecular Biology, v.42, p.55-76, 1991.

EMBRAPA - Empresa Brasileira de Pesquisa Agropecuária. Centro Nacional de Pesquisa de Solos. Rio de Janeiro: Sistema Brasileiro de Classificação de Solos. Brasília: Sistema de Produção de Informação, 1999. 412p. 
EMBRAPA - Empresa Brasileira de Pesquisa Agropecuária. Centro Nacional de Pesquisa de Agroindústria Tropical. Dados climatológicos: Estação de Pentecoste. Fortaleza: Embrapa Agroindústria Tropical, 2001. 14p. Boletim Agrometeorológico, 26

Endres, L.; Souza, J. L. de; Teodoro, I.; Marroquim, P. M. G.; Santos, C. M. dos; Brito, J. E. D. de. Gas exchange alteration caused by water deficit during the bean reproductive stage. Revista Brasileira de Engenharia Agrícola e Ambiental, v.14, p.11-16,2010.

Flexas, J.; Bota, J.; Galmés, J.; Medrano, H.; Ribas-Carbo, M. Keeping a positive carbon balance under adverse conditions: responses of photosynthesis and respiration to water stress. Physiologia Plantarum, v.127, p.343-352, 2006.

Gollan, T.; Passioura, J. B.; Munns, R. Soil water status affects stomatal conductance of fully turgid wheat and sunflower leaves. Australian Journal of Plant Physiology, v.13, p.459464, 1986.

Heckler, J. C. Sorgo e girassol no outono-inverno, em sistema plantio direto, no Mato Grosso do Sul, Brasil. Ciência Rural, v.32, p.517-520, 2002.

Hecknenberger, U.; Roggatz, U.; Schurr, U. Effect of drought stress on the cytological status in Ricinus communis. Journal of Experimental Botany, v.49, p.181-189, 1998.

Holanda, A. Biodiesel: Combustível para cidadania. Brasília: Plenarium, 2006. 30p. Série Ação Parlamentar, 326.

Inoue, M. T.; Martins, E. G. Variação sazonal da fotossíntese e clorofila em progênies de Grevillea robusta Cunn. Revista Ciências Exatas e Naturais, v.8, p.113-124, 2006.

Koutroubas, S. D.; Papakosta, D. K.; Doitsinis, A. Water requirements for castor oil crop (Ricinus communis L.) in a Mediterranean climate. Journal of Agronomy \& Crop Science, v.184, p.33-41, 2000.

Lacerda, R. D. de; Guerra, H. O. C.; Barros Júnior, G. Influência do déficit hídrico e da matéria orgânica do solo no crescimento e desenvolvimento da mamoneira BRS 188 Paraguaçu. Revista Brasileira de Ciencias Agrárias, v.4, p.440-447, 2009.

Larcher, W. Ecofiosiologia vegetal. São Carlos: Rima, 2004. 531p.

Liberato, M. A. R.; Gonçalves, J. F. de C.; Chevreuil, L. R.; Nina Junior, A. da R.; Fernandes, A. V.; Santos Junior, U. M. dos. Leaf water potential, gas exchange and chlorophyll a fluorescence in acariquara seedlings (Minquartia guianensis Aubl.) under water stress and recovery. Brazilian Journal of Plant Physiology, v.18, p.315-323, 2006.

Marenco, R. A.; Lopes, N. F. Fisiologia vegetal: Fotossíntese, respiração, relações hídricas e nutrição mineral. 1.ed. Viçosa: UFV, 2005. 451p.

Martim, S. A.; Santos, M. P.; Peçanha, A. L.; Pommer, C.; Campostrini, E.; Viana, A. P.; Façanha, A. R.; Bressan-Smith, R. Photosynthesis and cell respiration modulated by water deficit in grapevine (Vitis vinifera L.) cv. Cabernet Sauvignon. Brazilian Journal of Plant Physiology, v.21, p.95$102,2009$.

Nascimento, R. do. Efeito de diferentes disponibilidades de água sobre alguns parâmetros de crescimento de plantas de mamona em estádio vegetativo. Revista Educação Agrícola Superior, v.22, p.45-47, 2007.
Naves-Barbiero, C. C.; Franco, A. C.; Bucci, S. J.; Goldstein, G. Fluxo de seiva e condutância estomática de duas espécies lenhosas sempre - verdes no campo sujo e cerradão. Revista Brasileira de Fisiologia Vegetal, v.12, p.119-134, 2000.

Oliveira, M. A. J. de; Bovi, M. L. A; Machado, E. C; Assis, M. M. de; Habermann, G; Rodrigues, J. D. Fotossíntese, condutância estomática e transpiração em pupunheira sob deficiência hídrica. Scientia Agricola, v.59, p.59-63, 2002.

Pereira, P. G; Bergonci, J. I; Bergamaschi, H; Rosa, L. M. G; França, S. Efeitos de diferentes níveis de déficit hídrico na fotossíntese e condutância foliar em milho. Revista Brasileira de Agrometeorologia, v.11, p.53-62, 2003.

Santos, A. C. dos; Andrade, A. P. de; Lima, J. R. de S.; Silva, I. de F. da; Cavalcante, V. R. Variabilidade temporal da precipitação pluvial: nível de nitrogênio no solo e a produtividade de cultivares de girassol. Ciência Rural, v.32, p.757-764, 2002.

Sassaki, R. M; Machado, E. C. Trocas gasosas e condutância estomática em duas espécies de trigo em diferentes teores de água no solo. Pesquisa Agropecuária Brasileira, v.34, p.1571-1579, 1999.

Sausen, T. L. Respostas fisiológicas de Ricinus Communis à redução na disponibilidade de água no solo. Porto Alegre: UFRS, 2007. 71p.

Schurr, U.; Heckenberger, U.; Herdel, K.; Walter, A.; Feil, R.; Leaf development in Ricinus communis during drought stress: dynamics of growth processes, of cellular structure and of sink-source-transition. Journal of Experimental Botany, v.51, p.1515-1529, 2000.

Severino L. S.; Milani, M.; Morais, C. R. de A.; Gondim, T. M. de S. Cardoso, G. D. Avaliação da produtividade e teor de óleo de dez genótipos de mamoneira cultivados em altitude inferior a 300 metros. Revista Ciência Agronômica, v.37, p.188-194, 2006.

Silva, E. C. da; Nogueira, R. J. M. C.; Azevedo Neto, A. D. de; Santos, V. F. dos. Comportamento estomático e potencial da água da folha em três espécies lenhosas cultivadas sob estresse hídrico. Acta Botanica Brasilica, v.17, p.231-246, 2003.

Silva, V. Características fisiológicas de cultivares de mamoneira (Ricinus communis L.) no Recôncavo Baiano. Cruz das Almas: UFRB, 2008. 73p. Dissertação Mestrado

Souza, A. dos S; Távora, F. J. A. F; Pitombeira, J. B; Bezerra, F. M. L. Épocas de plantio e manejo da irrigação para a mamoneira. I - Componentes de produção. Revista Ciência Agronômica, v.38, p.414-421, 2007.

Souza, C. R. de; Soares, Â. M.; Regina, M. de A. Trocas gasosas de mudas de videira, obtidas por dois porta-enxertos, submetidas à deficiência hídrica. Pesquisa Agropecuária Brasileira, v.36, p.1221-1230, 2001.

Taiz, L.; Zeiger, E. Fisiologia vegetal. 4.ed. Porto Alegre: Artmed, 2009. 819p.

Tezara, W.; Marín, O.; Rengifo, E.; Martinez, D.; Herrera, A. Photosynthesis and photoinhibition in two xerophytic shrubs during drought. Photosynthetica, p.37-45, 2005. 